\title{
Prevalência de infecções urinárias em pacientes atendidos pelo sistema único de saúde e sua suscetibilidade aos antimicrobianos
}

\section{Prevalence of urinary infections in patients served by the national health system and their suscetibility to antibiotics}

Mariana Casteleti Beraldo-Massoli', Caroline Peters Pigatto de Nardi², Lilian Cristina Makino ${ }^{3}$, Ruben Pablo Schocken-Iturrino ${ }^{4}$

\begin{abstract}
RESUMO
As infecções do trato urinário são comuns tanto nosocomial quanto na comunidade. As principais bactérias comumente envolvidas são bastonetes Gram-negativos ou cocos Gram- positivos. Tratamentos inadequados destas infecções agravam o problema de resistência antimicrobiana. O presente trabalho teve como objetivo determinar a frequência dos patógenos causadores de infecção urinária em pacientes atendidos em postos de saúde da região de Jaboticabal, SP, no período de janeiro a abril de 2009, bem como conhecer o perfil de suscetibilidade antimicrobiana das espécies bacterianas isoladas. Foram analisadas 84 uroculturas positivas nos meios CLED e MacConkey e, de acordo com as características morfológicas, as mesmas foram identificadas por provas bioquímicas direcionadas. As mulheres apresentaram-se mais susceptíveis às infecções do trato urinário em $88 \%$ das amostras. $A$ Escherichia coli foi a bactéria predominante em $62 \%$ das amostras, seguida de Enterobacter sp. (9\%), Klebsiella pneumoniae, Staphylococcus saprophyticus e Staphylococcus sp com 6\% cada, Proteus mirabilis (5\%), Streptococcus sp (2,4\%), Staphylococcus aureus e Streptococcus do grupo D com $1,2 \%$ cada e Klebsiella oxytoca com 1\%. A faixa etária de pacientes mais acometidos foi a de 13 a 40 anos correspondendo a $43 \%$ dos pacientes com infecção do trato urinário (ITU) atendidos.
\end{abstract}

Palavras-chave: Urina. Resistência Microbiana a Antibióticos. Relações Hospedeiro-Patógeno.

\section{Introdução}

A infecção do trato urinário (ITU) acomete homens e mulheres em todas as idades. Quanto à etiologia, existem variáveis relacionadas ao sexo, idade, estado geral do paciente, uso prévio de antibióticos e aquisição de infecções urinárias dentro ou fora do ambiente hospitalar. ${ }^{1}$ Neste contexto, os fatores de virulência bacterianos são importantes, pois influenciam no grau de acometimento da infecção. ${ }^{2}$ Os agen-
1. Doutoranda em microbiologia, Faculdade de Ciencias Agrárias e Veterinárias UNESP Campus Jaboticabal.

2. Pós doutoranda e Professora do Instituto Federal de São Paulo, Campus Avançado de Matão.

3. Pós doutoranda em aqüicultura pelo Centro de aqüicultura da UNESP Campus Jaboticabal (Caunesp).

4. Professor Titular da Faculdade de Ciencias Agrárias e Veterinárias UNESP Campus Jaboticabal.
Correspondência: Faculdade de Ciências Agrárias e Veterinárias (FCAV). Universidade Estadual Paulista "Júlio de Mesquita Filho" Campus Jaboticabal. Departamento de Microbiologia - Laboratório de Bactérias Anaeróbias. E-mail: maricberaldo@yahoo.com.br

Artigo recebido em 23/02/2012 Aprovado para publicação em 14/06/2012 
tes etiológicos frequentemente envolvidos são microrganismos Gram-negativos entéricos, especialmente a Escherichia coli, tanto na comunidade quanto no ambiente hospitalar. ${ }^{3}$ Os cocos Gram-positivos também podem ser agentes de infecção como o Staphylococcus sp. e o Streptococcus sp. ${ }^{4}$

A utilização incorreta dos antibióticos no tratamento deste tipo de enfermidade induz a uma pressão seletiva sobre o agente, favorecendo a multiplicação de cepas bacterianas resistentes. Assim, o emprego de doses curtas ou única não é aconselhado no tratamento da ITU, pois poderá induzir resistência bacteriana. ${ }^{5}$ Além disso, a disseminação desses agentes ocorre particularmente quando as medidas básicas no controle das infecções hospitalares não são respeitadas. ${ }^{6}$

A fim de incrementar e atualizar as informações sobre os agentes envolvidos em ITU, o presente trabalho teve como objetivo identificar os patógenos causadores de infecção urinária em pacientes atendidos em postos de saúde da região de Jaboticabal, SP, no período de janeiro a abril de 2009 e determinar do perfil de suscetibilidade antimicrobiana das espécies isoladas nestes pacientes.

\section{Material e Métodos}

Foram identificadas 80 uroculturas positivas de pacientes de todas as idades oriundos do sistema único de saúde (SUS) da região de Jaboticabal, SP. A coleta foi realizada no Laboratório da cidade que atende a população, seguindo os seguintes critérios: a amostra preferencialmente deve ser a primeira urina da manhã, o paciente deve fazer a lavagem da região genital, enxaguar e não enxugar e coletar a urina após desprezar o primeiro jato em um frasco esterilizado. No caso de recém-nascidos e crianças coloca-se o coletor infantil, que pode ser trocado a cada 30 minutos até a criança urinar. Os frascos foram devidamente identificados e datados.

Após a coleta, as urinas foram semeadas no meio de cultura CLED e MacConkey, com o auxílio de uma alça calibrada de $0,001 \mathrm{~mL}$, sendo a placa incubada a $37^{\circ} \mathrm{C}$ durante 24 horas. Após este período foi realizada a contagem de colônias. Nos casos de crescimento precário ou ausente, a placa era descartada apontando resultado negativo. Nos casos em que eram observadas dez ou mais colônias uniformes foram realizadas a coloração de Gram, as colônias Gram positivas e em forma de cocos foram submetidas à prova da catalase. As amostras positivas no referido teste indicaram a presença de Staphylococcus sp e as amostras negativas indicaram presença de Streptococcus sp. Após a identificação, os isolados foram submetidos ao teste de sensibilidade antimicrobiana. No caso dos agentes Gram-negativos, as colônias foram submetidas a uma série bioquímica com o kit para enterobactérias IAL (Newprov®) e posteriormente submetidas ao teste de suscetibilidade a antimicrobianos.

O perfil de suscetibilidade a antimicrobianos foi determinado utilizando o método de Kirby-Bauer, baseado na difusão de discos de antimicrobianos em ágar Müller-Hinton, segundo as recomendações do NCCLS. ${ }^{7}$ As cepas foram cultivadas em meio TSA durante 18 horas em estufa bacteriológica a $37^{\circ} \mathrm{C}$. Três a cinco colônias foram suspensas em solução salina estéril a $0,85 \%$ até atingir uma turvação equivalente ao tubo 0,5 na escala de Mac Farland (aproximadamente 108 microrganismos/mL). A suspensão foi inoculada em placas de ágar Müller-Hinton, com o auxílio de swab estéril, por toda a superfície do meio, para a obtenção de crescimento bacteriano confluente. Discos impregnados com os antimicrobianos selecionados foram depositados nas placas com o auxílio de uma pinça estéril. Os seguintes antimicrobianos foram testados: Norfloxacina, Cloranfenicol, Tetraciclina, Rifampicina, Rifamicina, Gentamicina, Ampicilina, Amicacina, Tobramicina, Cefalotina, Cefoxitina, Cefotaxima, Ácido Nalidíxico, Nitrofurantoína, Acido pipemidico, Oxacilina, Penicilina, Sulfametoxazoltrimetropim, Aztreonam, Vancomicina, Pefloxacina, Ceftazidina, Amoxicilina, Cefalexina, Clindamicina e Novobiocina. Após o período de incubação, o diâmetro dos halos de inibição foi medido e os resultados foram interpretados de acordo com as normas do NCCLS.

O trabalho foi dividido em três faixas etárias, 0 a12 anos, de 13 a 40 (escolhida por envolver a primeira menstruação, uma maior freqüência de relações sexuais e gravidez) e mais de 40 anos. Desse modo foi analisada a porcentagem de acordo com a idade, sexo e a frequência das bactérias isoladas.

\section{Resultados e Discussão}

O presente trabalho obteve a maior frequência de infecção urinária em mulheres, com 88\% dos casos, e o grupo etário que registrou mais ITU foi o de 13-40 anos, correspondendo a 43\% desses pacientes, faixa etária essa mais predisposta a infecções uma vez que ocorre períodos menstruais que podem alte- 
rar o $\mathrm{pH}$, frequentes relações sexuais, gravidez entre outros fatores.

As enterobactérias foram o grupo de bactérias predominante neste estudo com $83 \%$ dos casos, sendo a Escherichia coli presente em $75 \%$ das infecções, seguido por Enterobacter sp (11\%), Klebsiella pneumoniae (7\%), Proteus mirabilis $(5,6 \%)$ e Klebsiella oxytoca $(1,4 \%)$.

Entre os cocos Gram-positivos (17\%), Staphylococcus saprophyticus e Staphylococcus sp foram os mais frequentes com $36 \%$, seguido por Streptococcus sp (14\%), Staphylococcus aureus e Streptococcus Grupo D, com $7 \%$.

O antibiótico que mostrou maior resistência foi a ampicilina com indice de 55\%, seguido pela tetraciclina (51\%), ácido nalidíxico (45\%), ácido Pipemidico e sulfametoxazol (39\%) cada, amoxicilina (33\%), Ceftazidina (26\%), norfloxacina (24\%), cloranfenicol $(18 \%)$, cefalotina (15\%), tobramicina (11\%), amicacina (10\%), Perfloxacina (8\%), Aztreonan e Novobiocina (6\%), nitrofurantoína e cefalexina (5\%), penicilina (4\%), cefoxitima, Cefotaxima ( $2 \%)$ e oxacilina (1\%) (Tabela 1).

Comparando as enterobacterias, notou-se que os perfis de resistência foram semelhantes. Entretanto houve sete cepas de Escherichia coli resistentes a perfloxacina. Três cepas de Escherichia coli e duas de Proteus mirabilis foram resistentes ao aztreonan e uma cepa de Enterobacter $s p$ foi resistente a cefotaxima.

Cocos Gram-positivos também foram suscetíveis aos antibióticos seguintes: rifampicina, gentamicina, cefalotina, nitrofurantoína, Aztreonan, Vancomicina, Perfloxacina, cefalexina e clindamicina. Para Oxacilina e Vancomicina, nenhuma espécie de Staphylococcus foi resistente.

Existe uma co-selecção de resistência à ampicilina e trimetoprim, o que é explicado pela existência de plasmídeos transmissíveis em Escherichia coli que codificam resistência a ambas8. Este trabalho mostra que as cepas resistentes a ampicilina não foram resistentes ao trimetoprim. A Gentamicina apresentou $100 \%$ de sensibilidade, mostrando assim que ainda é um antibiótico bom para ser usado em tratamentos. Seguido por amicacina, cefotaxima, nitrofurantoína, cefoxitina, tobramicicna, aztreonam, norfloxacina, cloranfenicol, cefalotina, ceftazidina, amoxicilina, trimetoprim, ácido nalidíxico, ácido pipemídico, tetraciclina, cefalexina, ampicilina, perfloxacina, vancomicina, rifampicina, oxacilina, penicilina, clindamicina e rifamicina, como mostra a Tabela 1.
Observou-se um aumento na resistência à amoxicilina e sulfametoxazol-trimetoprim em isolados de Escherichia coli, o principal responsável por infecções do trato urinário em pacientes ambulatoriais. ${ }^{9} \mathrm{No}$ presente estudo foi observado uma resistência 33\% para a amoxicilina e $39 \%$ para sulfametoxazol-trimetoprim.

\section{Tabela 1}

A tabela apresenta a suscetibilidade das bacterias isoladas de infecções do trato urinário aos antimicrobianos testados.

\begin{tabular}{lrr}
\hline Antibiotico & Sensibilidade & Resistencia \\
\hline Norfloxacina & $64(76 \%)$ & $20(24 \%)$ \\
Cloranfenicol & $64(76 \%)$ & $15(18 \%)$ \\
Tetraciclina & $38(45 \%)$ & $43(51 \%)$ \\
Rifampicina & $11(13 \%)$ & - \\
Rifamicina & $6(7 \%)$ & $4(5 \%)$ \\
Gentamicina & $84(100 \%)$ & - \\
Ampicilina & $33(39 \%)$ & $46(55 \%)$ \\
Amicacina & $78(93 \%)$ & $8(10 \%)$ \\
Tobramicina & $70(83 \%)$ & $9(11 \%)$ \\
Cefalotina & $60(71 \%)$ & $13(15 \%)$ \\
Cefoxitima & $72(86 \%)$ & $2(2 \%)$ \\
Cefotaxima & $78(93 \%)$ & $2(2 \%)$ \\
Ac. Nalidixico & $44(52 \%)$ & $38(45 \%)$ \\
Nitrofurantoina & $77(92 \%)$ & $4(5 \%)$ \\
Ac.pipemídico & $44(52 \%)$ & $33(39 \%)$ \\
Oxacilina & $10(12 \%)$ & $1(1 \%)$ \\
Penicilina & $8(10 \%)$ & $3(4 \%)$ \\
Sulf.trimetroprim & $47(56 \%)$ & $33(39 \%)$ \\
Aztreonam & $67(80 \%)$ & $5(6 \%)$ \\
Vancomicina & $13(15 \%)$ & $7(8 \%)$ \\
Perfloxacino & $24(29 \%)$ & $28(33 \%)$ \\
Amoxicilina & $53(63 \%)$ & $4(5 \%)$ \\
Cefalexina & $34(40 \%)$ & $5(6 \%)$ \\
Ceftazidina & $56(67 \%)$ & - \\
Novindamicina & $8(10 \%)$ & - \\
\hline
\end{tabular}


Todos os antibióticos beta-lactâmicos, tais como penicilina G, ampicilina, amoxicilina, cefalexina e cefaclor são ativos contra enterobacteriaceae. ${ }^{10}$ As quinolonas de maior espectro como ciprofloxacina devem ser reservadas para uso em casos de impossibilidade do uso de outras drogas para não induzir resistência. O autor descreve também que o grupo de Tetraciclinas (tetraciclina, oxitetraciclina, doxiciclina, minociclina) é especialmente eficaz no tratamento de infecções com Chlamydia trachomatis.

O uso inadequado dos antimicrobianos pode levar a resistência bacteriana a médio e longo prazo, uma vez que as bactérias apresentam genes relacionados a resistência e esses são passados de uma bactéria para a outra através de plasmídeos, o que preocupa cada vez mais os pesquisadores, pois a cada ano aparecem novas resistências, principalmente a antibióticos de segunda e terceira gerações. Por esta razão, os antibioticos devem ser cada vez mais controlados e administrados com precaução e indicação precisa.

\section{Agradecimentos}

O Laboratório Regional que colaborou com esta pesquisa.

A Coordenação de Aperfeiçoamento de Pessoal de Nível Superior (CAPES) pela concessão da bolsa de estudo.

\begin{abstract}
The urinary tract infections are common in both nosocomial and community. The main bacteria commonly involved are Gram-negative or Gram-positive cocci. Inadequate treatment of these infections exacerbates the problem of antimicrobial resistance. This study aimed to determine the frequency of pathogens causing urinary tract infection in patients from clinics in Jaboticabal, SP, from January to April 2009, as well as to know the antimicrobial susceptibility of bacterial species isolated. Eighty four urine cultures were analysed on MacConkey and CLED means and, according to the morphological characteristics, they were identified by biochemical directed. Women were more susceptible to urinary tract infections in $88 \%$ of the samples. Escherichia coli bacteria was predominant in $62 \%$ of the samples, followed by Enterobacter sp. (9\%), Klebsiella pneumoniae, Staphylococcus saprophyticus, and Staphylococcus sp with $6 \%$ each, Proteus mirabilis (5\%), Streptococcus sp (2.4\%), Staphylococcus aureus and Streptococcus $\mathrm{D}$ at $1.2 \%$ each and Klebsiella oxytoca $1 \%$. The age group most affected patients was 13 to 40 years old, accounting for $43 \%$ of patients with urinary tract infection (UTI) treated.
\end{abstract}

Key Words: Urine. Drug Resistence, Microbial. Host-Pathogen Interactions.

\section{Referencias}

1. Valiquette L. Urinary tract infections in women. Can $\mathrm{J}$ Urol. 2001; 8: 6-12.

2. Funfstuck R, Smith JW, Tschape H, Stein G. Pathogenetic aspects of uncomplicated urinary tract infection: recent advances. Clin Nephrol. 1997; 47: 13-8.

3. Dias Neto JA; Magalhães da Silva LD; Martins ACP; Tiraboschi RB; Domingos AA; Suaid HJ; Tucci Jr S; et al. Prevalence and bacterial susceptibility of hospital acquired urinary tract infection. Acta Cir Bras. 2003; 18: 36-8.

4. Koneman EW, Allen SD, Janda WM, Schereckenberger PC Winn Jr. WC. Diagnóstico Microbiológico: Texto e atlas colorido 2001.5 ed. Rio de Janeiro. MEDSI.

5. Koch CR; Ribeiro JC; Schnor OH; Zimmermann BS; Müller FM; Agostin JD; et al. Resistência antimicrobiana dos uropatógenos em pacientes ambulatoriais, 2000-2004. Rev Soc Bras Med Trop. 2008; 41:277-81.
6. Padoveze MC; Oliveira EL. Bactérias multirresistentes. Disponível em: http://www.hospvirt.org.br/enfermagem/port/ bacterias_multi.html. Acessado em 10/02/2012.

7. National Committee for Clinical Laboratory Standards. 2000. Performance standards for antimicrobial disk susceptibility tests, 7th ed. Approved standard M2-A7.

8. Berdichevski RH, Zanardo JC, Soibelman M, Antonello I. Prevalência de uropatógenos e sua resistência aos antimicrobianos em uroculturas realizadas no Hospital São Lucas da PUCRS. Rev AMRIGS. 1998; 42: 137-42.

9. Bail L, Ito CAS, Esmerino LA. Infecção do trato urinário: comparação entre o perfil de suscetibilidade e a terapia empírica com antimicrobianos; RBAC. 2006; 38: 51-6.

10. Heilberg IP, Schor N. Abordagem diagnóstica e terapêutica na infecção do trato urinário. Rev. Assoc. Med. Bras.2002; 49: 109-16. 